\title{
Intestinal metaplasia of the urinary bladder: is smoking a risk factor?
}

\begin{abstract}
Background: Cystitis glandularis is relatively a common appearance in the urinary bladder; it results from the metaplasia of the urothelium due to chronic irritation into intestinal epithelium.

Case Presentation: A 49 year- old gentleman, who is hypertensive and has history of heavy smoking for the last 30 years, presented to Urology clinic with terminal hematuria, suprapubic pain for 4 years, and irritative voiding symptoms for 8 months. Apart from normal clinical exam, radiology images showed a polypoid bladder mass after which he underwent TURBT.

Conclusion: Reviewing the literature, different risk factors were postulated for development of intestinal metaplasia of the urinary bladder, which result from chronic irritation of the urothelium including cystitis, stones, bladder exstrophy, ureteral reimplantation and instrumentation, but smoking per se was not. By reviewing our patient, neither any of the risks mentioned were included which raises the question that is smoking a risk factor for intestinal metaplasia
\end{abstract}

Volume 4 Issue $6-2017$

\author{
Alhazmi AM, Moazin MS, Binmahfooz AM, \\ Mahmoud AR, Fatani HA \\ King Fahad Medical City, Saudi Arabia
}

\begin{abstract}
Correspondence: Alhazmi AM, King Fahad Medical City, Riyadh, Saudi Arabia, Tel 504660900,
\end{abstract}

Emaildramhazmi@gmail.com

Received: March 18, 2017| Published: June 07, 2017

\section{Background}

Cystitis Glandularis is not an uncommon pathologic finding, it usually affects the trigone of the urinary bladder, but other parts of the urothelium are not immune, in this condition the normal urothelium undergoes metaplasia into intestinal like epithelium. By literature review it has been suggested that chronic irritation is the main causative factor; cystitis, stones, bladder exstrophy, ureteral reimplantation, and prolonged instrumentation have been implicated as factors of irritation. However, smoking hasn't been related as a cause of such disease.

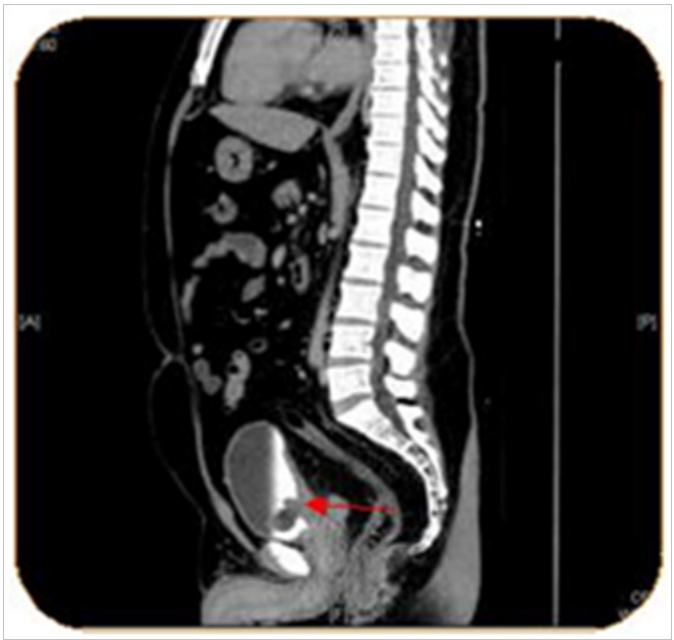

Figure I A polypoidal mass and thickening of the trigone, no lymphadenopathy or metastasis could be seen.

\section{Case presentation}

A 49 year-old gentleman, hypertensive on calcium channel and Beta blockers, and known to be a heavy smoker for more than 30 years, has been referred to our center complaining of terminal hematuria and suprapubic pain for a period of 4 years, irritative voiding symptoms for the last 8 months, and a bladder ultrasound showing a mass measuring $2.8 \times 2.3 \mathrm{~cm}$. Apart from appendectomy and left varicocelectomy done 20 years ago, there was no history of recurrent UTIs, STDs, kidney or bladder stones, instrumentation or surgery of the urinary tract. Multiple urine cultures were done outside showing no infection. Abdominal examination was unremarkable, and a digital rectal exam showed a small, firm, and smooth prostate.

A complete blood count, liver function test, urine culture and PSA were all within normal ranges. Urine cytology revealed atypical cells. CT abdomen and pelvis with I.V contrast showed a $3.1 \times 2.4 \times 3 \mathrm{~cm}$ polypoidal mass of the trigone (Figure 1). Afterwards, the patient underwent cystoscopy which showed a solid florid mass extending from the trigone to the posterior wall of the urinary bladder, TURBT was carried out. The Histopathology slides showed cystitis cystica with cystitis glandularis (Colonic metaplasia) Figure (2-5).

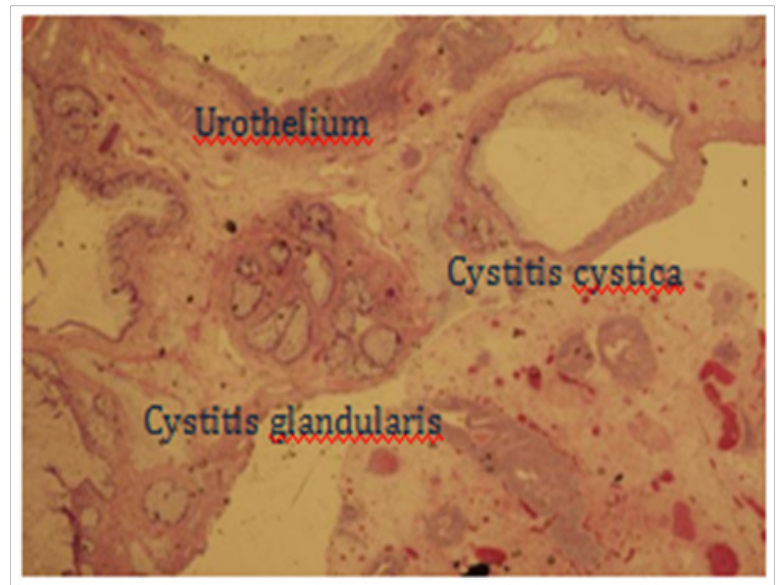

Figure 2 Cystitis glandularis. 


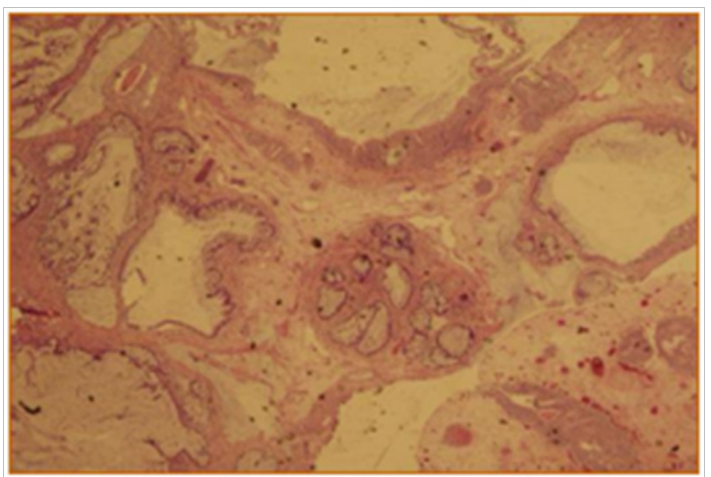

Figure 3 Both figures 2, 3 show Cystitis glandularis-complex glandular structure lined by mucin producing cells connecting with the overlying transitional epithelium resembles colonic mucosa with goblet cells and mucin extravasation.

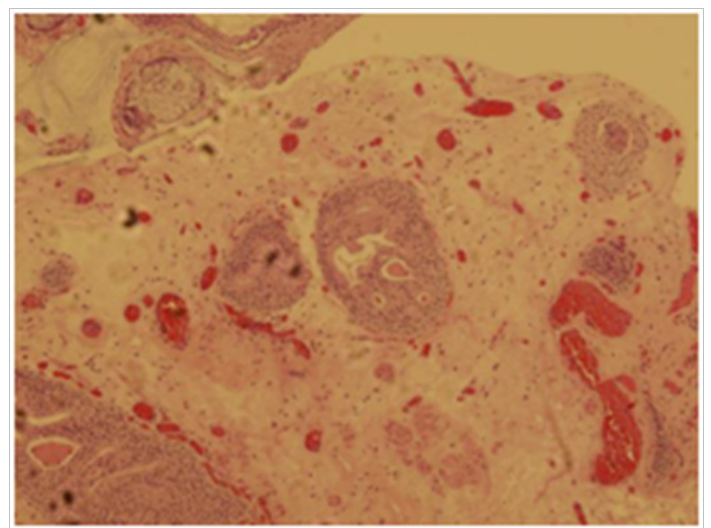

Figure 4 View of Cystitis cystica. Each of the epithelial nests has a central lumen.

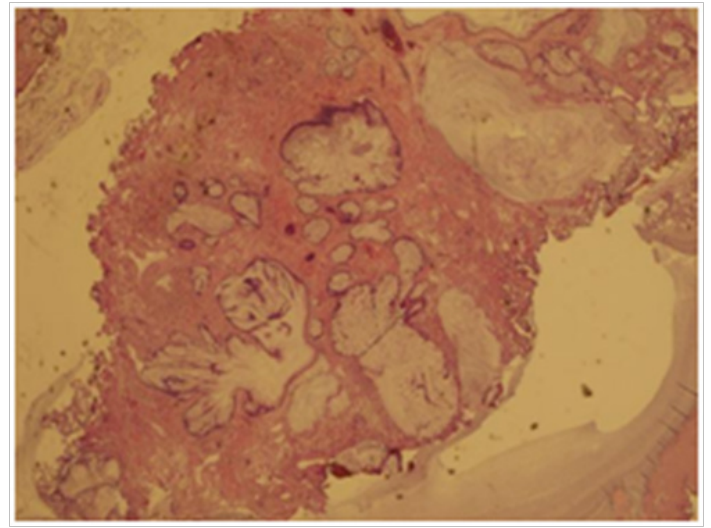

Figure 5 Complex glandular structure with mucin producing cells and mucin extravasation.

\section{Discussion}

Cystitis glandularis is a benign proliferative disease of the bladder mucosa. It initially appears as submucosal masses of epithelial cells (Brunn's nest) followed by cavitations of such structures, central necrosis, or serosal secretion. This result in the appearance of miliary cystic structures lined with cubic or columnar epithelium and filled with serosal fluid, termed cystitis cystica. The condition is termed cystitis glandularis when there is metaplasia with a mucussecreting epithelium. ${ }^{1}$ It is thought to be induced by chronic irritation and inflammation of the urothelium, ${ }^{2}$ known causes documented in literature include bladder calculi, ${ }^{3}$ chronic catheterization in paraplegics, bladder schistosomiasis ${ }^{4}$ and chronic bacterial cystitis. ${ }^{5}$ The cytologic finding of glandular cells in a urine specimen is unusual. The differential diagnosis ranges from benign conditions such as cystitis glandularis to adenocarcinoma. Glandular cells of cystitis glandularis with intestinal metaplasia have a bland cytologic appearance. If detected in a urine cytology specimen colonic metaplasia can be reported. ${ }^{6}$

Patients of CG usually present with symptoms related to bladder irritation such as dysuria, urgency, frequency, hematuria or abdominal pain, the most common site is the trigone. ${ }^{7}$ By looking through our patient's history, and reviewing the literature, the causes of cystitis glandularis weren't found. The only potential cause could be related was smoking raising the question that could smoke be a direct cause of intestinal metaplasia of the urothelium?

\section{Acknowledgments}

None.

\section{Conflicts of Interset}

None.

\section{References}

1. Young RH, Bostwick DG. Florid cystitis glandularis of intestinal type with mucin extravasation: a mimic of adenocarcinoma. Am J Surg Pathol. 1996;20(12):1462-1468.

2. Bell TE, Wendel RG. Cystitis glandularis: benign or malignant? J Urol. 1968;100(4):462-465.

3. Fein RL, Winton L, Gomez RR, eta 1. Bladder calculi enveloped by extensive cystitis glandularis: case report. J Urol. 1983;130(3):558-559.

4. Zahran MM, Kamel M, Mooro H, et al. Bilharziasis of urinary bladder and ureter: comparative histopathologic study. Urology. 1976;8(1):73-79.

5. Belman AB. The clinical significant of cystitis cystica in girls: Results of a prospective study. J Urol. 1978;119(5):661-663.

6. Pantanowitz L, Otis CN. Cystitis glandularis, Diagn Cytopathol. 2008;36(3):181-182.

7. Andersen JA, Hansen BF. The incidence of cell nests, cystitis cystica and cystitis glandularis in the lower urinary tract revealed by autopsies. J Urol. 1972;108(3):421-424. 